\title{
Evaluation of Hair Density in Different Ethnicities in a Healthy American Population Using Quantitative Trichoscopic Analysis
}

\author{
Mathew R. Birnbaum ${ }^{a}$ Beth N. McLellan ${ }^{a} \quad$ Jerry Shapiro ${ }^{c}$ Kenny Ye ${ }^{b}$ \\ Sophia D. Reid ${ }^{\text {a }}$ \\ ${ }^{a}$ Department of Medicine, Division of Dermatology, and ${ }^{b}$ Department of Epidemiology and Population Health, \\ Albert Einstein College of Medicine/Montefiore Medical Center, Bronx, NY, and ${ }^{\mathrm{C} T}$ The Ronald O. Perelman \\ Department of Dermatology, New York University School of Medicine, New York, NY, USA
}

\section{Keywords}

Trichoscopy · Hair density · Hispanic population · Ethnic hair · Alopecia

\begin{abstract}
Background: There is limited research into normative hair density values in individuals of Hispanic descent. Methods: In order to help establish baseline density values in these individuals, we evaluated the hair density in 99 Americans of Hispanic descent and compared them with the values in 44 individuals of African descent and 23 Caucasians. Participants were recruited from a New York City medical center and self-identified their ethnicity. Biracial individuals were excluded from the study. Results: The hair density means \pm SD ranged from $169 \pm 31$ to $178 \pm 33 / \mathrm{cm}^{2}$ in Americans of Hispanic descent, from $148 \pm 25$ to $160 \pm 27 / \mathrm{cm}^{2}$ in individuals of African descent, and from $214 \pm 28$ to $230 \pm 33 / \mathrm{cm}^{2}$ in Caucasian individuals. All differences in hair densities between the ethnicities were statistically significant ( $p$ values ranging from $3.03 \times 10^{-14}$ to 0.0249 ). Conclusion: While trichoscopy is not as accurate as invasive histological assessment of hair density or phototrichogram, it is still a reliable and fast method for assessing hair density. Increased aware-
\end{abstract}

\section{KARGER}

(c) 2017 S. Karger AG, Basel

E-Mail karger@karger.com

www.karger.com/sad ness of ethnic variances in hair density can help clinicians and researchers diagnose hair disorders, monitor response to therapy, and conduct hair-related research in these patients.

(c) 2017 S. Karger AG, Basel

\section{Introduction}

Research in normative hair density values has largely been conducted in Caucasian and Asian populations [1, 2]. There is a paucity of literature on hair density within the Hispanic population [3]. While previous research has shown that individuals of African descent have lower hair density compared with Caucasians, less is known about how hair density in the Hispanic population compares with other ethnicities $[4,5]$. Establishing normative values can help better identify the presence of disease and provide a useful baseline or target when researching and treating hair loss in this patient population. Using quantitative trichoscopic analysis, we sought to measure hair density in Americans of Hispanic descent. Trichoscopy is a fast and noninvasive method for evaluating hair density that has been successfully used in various research [6-8]. 


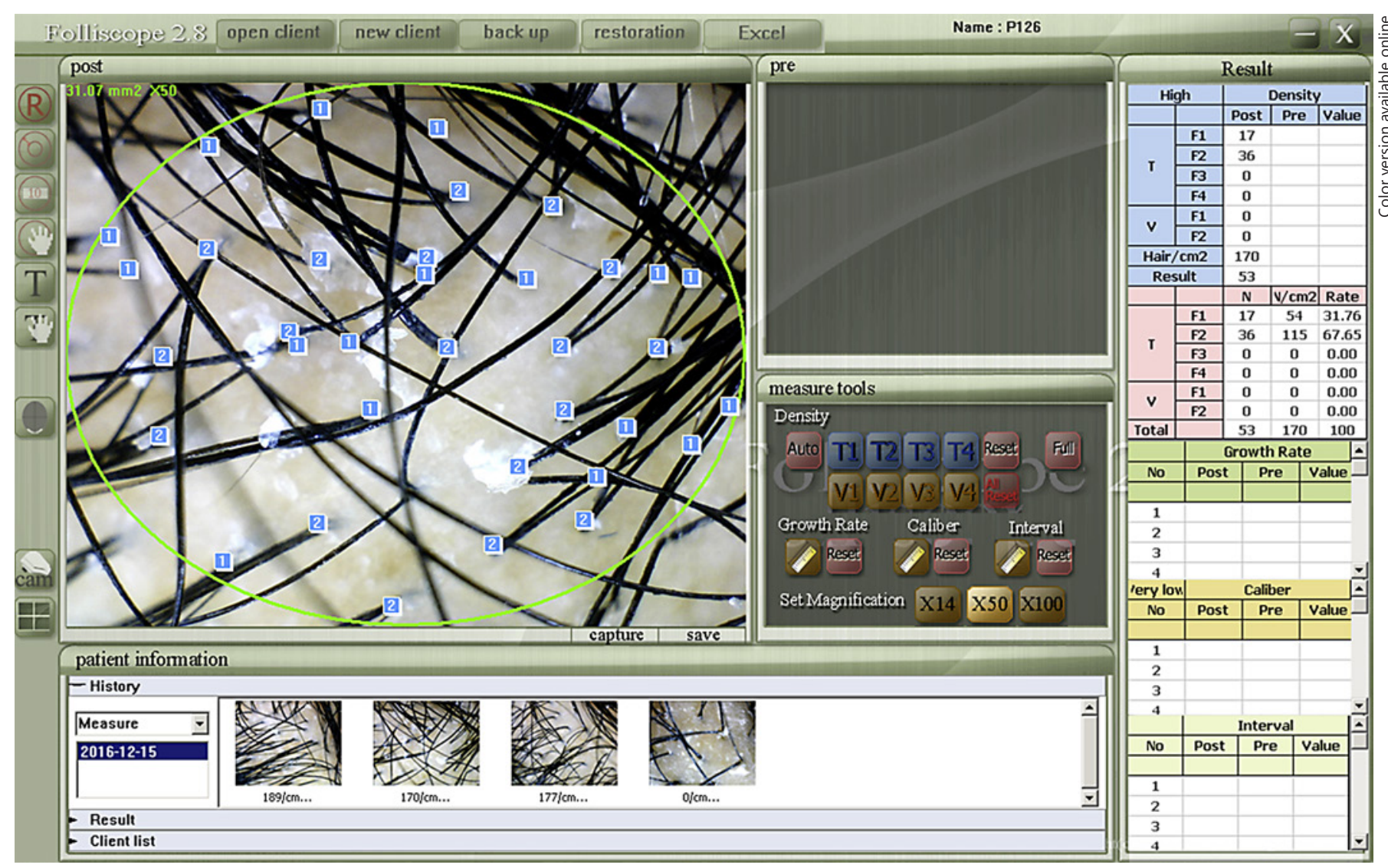

Fig. 1. Folliscope program. The figure shows a screenshot of the Folliscope software. The image of the scalp is taken at a 50-fold magnification corresponding to a $31.07 \mathrm{~mm}^{2}$ area. A single blue square label can denote up to 4 hairs.

\section{Methods}

The study was approved by the Albert Einstein College of Medicine institutional review board. Participants were recruited from Jacobi Medical Center's Ambulatory Clinic between October 2016 and February 2017. Participants needed to be between ages 18 and 65 , have a clinically normal-appearing scalp, a negative hair pull test, and self-reported the absence of uncontrolled systemic diseases (e.g., thyroid disease, connective tissue disease). Individuals selfidentified their ethnicity and biracial individuals were excluded. Hair washing or combing on the day of evaluation was not assessed or controlled for. At the conclusion of the study, a total of 99 Americans of Hispanic descent (71 females, 28 males), 44 individuals of African descent ( 32 females, 12 males), and 23 Caucasians ( $16 \mathrm{fe}$ males, 7 males) met the study criteria and were evaluated. Hair imaging and measurements were conducted using a hand-held USB trichoscopy system (Folliscope ${ }^{\circledR}$, LeedM Corporation, Fig. 1) [7]. Each patient's hair was parted down the middle and three images of the scalp were taken at roughly 12,24 , and $30 \mathrm{~cm}$ from the patient's glabella, corresponding to the frontal, vertex, and occipital scalp, respectively. The images were taken at a 50-fold magnification corresponding to a $31.07 \mathrm{~mm}^{2}$ area. All participants answered a brief questionnaire related to their demographics and hair (Table 1).

Hair Density Evaluation in Different Ethnicities

\section{Statistical Analysis}

Analyses were performed using a linear random effect model in the R package lme4 [9]. Subjects were treated as random effects to reflect the nature of the repeated measurements at the different scalp locations. The effects of location, ethnicity, and age on hair density were examined. The statistical significance $(p<0.05)$ of each factor is tested by a maximum likelihood ratio test between linear random effect models.

\section{Results}

Hair density differences between females and males were not statistically significant so they were evaluated together. The mean age was 40.2 years in the Americans of Hispanic descent group, 41.9 in the individuals of African descent group, and 34.7 in the Caucasian group (Table 1). All analyses took the age differences between the three ethnicities into account. The hair density means \pm SD at the frontal scalp, vertex, and occipital scalp for the three groups were: $174 \pm 32,178 \pm 33$, and $169 \pm 31 / \mathrm{cm}^{2}$ in the 
Americans of Hispanic descent group, $160 \pm 27,149 \pm 23$, and $148 \pm 25 / \mathrm{cm}^{2}$ in the individuals of African descent group, and $230 \pm 33,226 \pm 20$, and $214 \pm 28 / \mathrm{cm}^{2}$ in the Caucasian group (Table 2). Hair density differences between the three study groups for all three scalp locations were statistically significant (Table 2). Within each ethnicity separately, hair density differences between scalp locations were statistically significant (Table 2). In the Americans of Hispanic descent group, the hair density was highest at the vertex, while in individuals of African descent and Caucasians, the hair density was highest at the frontal scalp. When looking at all three ethnicities combined, the overall effect of age on hair density was a decrease in 0.33 hairs $/ \mathrm{cm}^{2}$ per year $(p=0.038)$. After controlling for ethnicity, there was no association between hair density and specific country of origin, hair product use, hair texture, or Fitzpatrick skin type in the three study groups.

\section{Discussion}

Our results show that Americans of Hispanic descent have a lower hair density than their Caucasian counterparts, but a higher density than individuals of African descent. For the purpose of the study, the term Americans of Hispanic descent included individuals from Central American, South America, and Spanish-speaking countries in the Caribbean and Europe. Patients self-identified their ethnicity and country of ancestry. Phototypes of selfidentified Americans of Hispanic descent ranged from Fitzpatrick skin types III to IV. This group self-reported their hair texture in its natural state as mainly curly, wavy, or straight and characterized the hair as course. While the classification of "Americans of Hispanic descent" can include individuals from various countries, our analysis did not reveal any significant variations in hair density related to country of origin, hair texture, or Fitzpatrick skin type. However, this finding may be related to our cohort being primarily comprised of individuals from the Dominican Republic, Puerto Rico, and Mexico.

For individuals of African descent, reported hair textures included mainly curly, coiled, kinky, and course. Despite similar reported hair textures and phototypes between Americans of Hispanic descent and individuals of African descent, our results still demonstrated a statistically significant difference in hair density between these populations, suggesting that hair density is related to factors other than physical phenotypes alone.

In 1999, Sperling [4] reviewed 4-mm punch biopsies of clinically normal scalps in 22 African Americans (mean
Table 1. Study participant demographics

\begin{tabular}{|c|c|c|c|}
\hline & $\begin{array}{l}\text { Hispanic } \\
\text { descent } \\
(n=99)\end{array}$ & $\begin{array}{l}\text { African } \\
\text { descent } \\
(n=44)\end{array}$ & $\begin{array}{l}\text { Caucasian } \\
(n=23)\end{array}$ \\
\hline \multicolumn{4}{|l|}{ Age } \\
\hline Mean & 40.2 years & 41.9 years & 34.7 years \\
\hline $18-25$ years & $12(12 \%)$ & $4(9 \%)$ & $7(30 \%)$ \\
\hline $26-35$ years & $22(22 \%)$ & $13(29 \%)$ & $8(35 \%)$ \\
\hline $36-45$ years & $33(33 \%)$ & $6(14 \%)$ & $3(13 \%)$ \\
\hline $46-55$ years & $19(19 \%)$ & $15(34 \%)$ & $2(9 \%)$ \\
\hline $56-65$ years & $13(13 \%)$ & $6(14 \%)$ & $3(13 \%)$ \\
\hline \multicolumn{4}{|l|}{ Gender } \\
\hline Female & $71(72 \%)$ & $32(73 \%)$ & $16(70 \%)$ \\
\hline Male & $28(28 \%)$ & $12(27 \%)$ & $7(30 \%)$ \\
\hline \multicolumn{4}{|l|}{ Family's country of origin ${ }^{\mathrm{a}}$} \\
\hline USA & $1(1 \%)$ & $17(39 \%)$ & $1(4 \%)$ \\
\hline Dominican Republic & $33(33 \%)$ & $0(0 \%)$ & $0(0 \%)$ \\
\hline Puerto Rico & $32(32 \%)$ & $0(0 \%)$ & $0(0 \%)$ \\
\hline Jamaica & $0(0 \%)$ & $20(45 \%)$ & $0(0 \%)$ \\
\hline Mexico & $19(19 \%)$ & $0(0 \%)$ & $0(0 \%)$ \\
\hline Russia & $0(0 \%)$ & $0(0 \%)$ & $11(48 \%)$ \\
\hline Other & $24(24 \%)$ & $9(20 \%)$ & $16(70 \%)$ \\
\hline \multicolumn{4}{|l|}{ Hair texture } \\
\hline Straight & $26(26 \%)$ & $4(9 \%)$ & $8(35 \%)$ \\
\hline Wavy & $34(34 \%)$ & $3(7 \%)$ & $10(43 \%)$ \\
\hline Curly & $35(36 \%)$ & $12(27 \%)$ & $5(22 \%)$ \\
\hline Coily & $2(2 \%)$ & $8(18 \%)$ & $0(0 \%)$ \\
\hline Kinky & $2(2 \%)$ & $17(39 \%)$ & $0(0 \%)$ \\
\hline Coarse & $53(54 \%)$ & $35(80 \%)$ & $10(44 \%)$ \\
\hline Fine & $46(46 \%)$ & $9(20 \%)$ & $13(56 \%)$ \\
\hline \multicolumn{4}{|l|}{ FPST } \\
\hline 1 & $1(1 \%)$ & $0(0 \%)$ & $5(22 \%)$ \\
\hline 2 & $3(3 \%)$ & $0(0 \%)$ & $13(56 \%)$ \\
\hline 3 & $51(52 \%)$ & $1(2 \%)$ & $5(22 \%)$ \\
\hline 4 & $43(43 \%)$ & $4(9 \%)$ & $0(0 \%)$ \\
\hline 5 & $1(1 \%)$ & $24(55 \%)$ & $0(0 \%)$ \\
\hline 6 & $0(0 \%)$ & $15(34 \%)$ & $0(0 \%)$ \\
\hline \multicolumn{4}{|l|}{ Hair styling methods ${ }^{\mathrm{a}}$} \\
\hline Heat styling & $17(17 \%)$ & $4(9 \%)$ & $4(17 \%)$ \\
\hline Relaxer & $6(6 \%)$ & $9(20 \%)$ & $0(0 \%)$ \\
\hline Perm & $0(0 \%)$ & $6(14 \%)$ & $0(0 \%)$ \\
\hline \multicolumn{4}{|l|}{ Keratin/Brazilian } \\
\hline Straightening & $5(5 \%)$ & $1(2 \%)$ & $0(0 \%)$ \\
\hline Hair dying & $49(49 \%)$ & $11(25 \%)$ & $10(44 \%)$ \\
\hline Natural hair styling & $42(42 \%)$ & $20(45 \%)$ & $13(57 \%)$ \\
\hline Other & $1(1 \%)$ & $6(14 \%)$ & $0(0 \%)$ \\
\hline
\end{tabular}

Figures are $n(\%)$, unless indicated otherwise. FPST, Fitzpatrick skin type.

${ }^{\text {a }}$ Multiple responses allowed; may not add up to $100 \%$.

age 32 years) and 12 Caucasian patients (mean age 36 years). He found that hair density was statistically different between the two groups, with approximately 169-177 hairs $/ \mathrm{cm}^{2}$ in African Americans and approximately 280 
Table 2. Hair density $\left(/ \mathrm{cm}^{2}\right)$ results by ethnicity and scalp location

\begin{tabular}{llllll}
\hline & $\begin{array}{l}\text { Hispanic } \\
\text { descent } \\
(n=99)\end{array}$ & $\begin{array}{l}\text { African } \\
\text { descent } \\
(n=44)\end{array}$ & $\begin{array}{l}p \text { value } \\
\text { (African vs. } \\
\text { Hispanic) }\end{array}$ & $\begin{array}{l}\text { Caucasian } \\
(n=23)\end{array}$ & $\begin{array}{l}p \text { value } \\
\text { (Caucasian vs. } \\
\text { Hispanic) }\end{array}$ \\
\hline Scalp location & & & & & \\
$\quad \begin{array}{l}\text { Frontal scalp } \\
\text { Vertex }\end{array}$ & $174 \pm 32$ & $160 \pm 27$ & 0.0249 & $230 \pm 33$ & $2.08 \times 10^{-12}$ \\
Occipital scalp & $178 \pm 33$ & $149 \pm 23$ & $5.87 \times 10^{-7}$ & $226 \pm 20$ & $1.13 \times 10^{-10}$ \\
& $169 \pm 31$ & $148 \pm 25$ & 0.000242 & $214 \pm 28$ & $1.7 \times 10^{-9}$ \\
\hline
\end{tabular}

hairs $/ \mathrm{cm}^{2}$ in Caucasians [4]. Using the phototrichogram technique, Loussouarn et al. [3] reported an overall hair density mean \pm SD of $215 \pm 68 / \mathrm{cm}^{2}$ in a cohort from Mexico (mean age 26 years) and $208 \pm 65 / \mathrm{cm}^{2}$ in a cohort from Latin America (mean age 27 years). In a different study, Loussouarn [5] evaluated hair density in African Americans and Caucasians (mean age 27 and 28 years, respectively, hair density mean \pm SD of $190 \pm 40$ and $227 \pm 55 /$ $\mathrm{cm}^{2}$, respectively). In both groups, they observed a higher hair density at the vertex compared with the temporal and occipital scalp and also noted a decrease in hair density in subjects over the age of 35 years [5]. Our patient cohorts' higher average age may explain the lower values we obtained as compared with these prior studies. Another factor that may have led to our lower values compared with published literature is that while trichoscopy is a fast and effective method of hair evaluation, it can underestimate hair density, partly due to the difficulty in visualizing gray hair [10]. However, our values in the Caucasian cohort were similar to those reported in Loussouarn and other published literature. This may suggest that our method of phototrichoscopy can potentially yield comparable hair density results to the more invasive and time-consuming trichogram and phototrichogram techniques [7].
Our results suggest that Americans of Hispanic descent and individuals of African descent have lower hair densities than Caucasians. From a practical standpoint, given the decreased density, these populations may be more cosmetically sensitive to hair loss since their ability to camouflage their hair loss may be lessened. A better understanding of hair density variations on the scalp can also be a useful tool when evaluating and selecting techniques for hair transplantation in individuals of Hispanic or African descent [11]. Moreover, these differences are important as awareness of ethnic variances in hair density can affect the ability to accurately diagnose hair disorders, monitor response to therapy, and conduct hairrelated research in these patients.

\section{Statement of Ethics}

The study was approved by the Albert Einstein College of Medicine institutional review board.

\section{Disclosure Statement}

The authors report no conflicts of interest. There was no funding for this work.

\section{References}

1 Ishino A, Takahashi T, Suzuki J, Nakazawa Y, Iwabuchi T, Tajima M: Contribution of hair density and hair diameter to the appearance and progression of androgenetic alopecia in Japanese men. Br J Dermatol 2014;171:10521059.

2 Ko JH, Huang YH, Kuo TT: Hair counts from normal scalp biopsy in Taiwan. Dermatol Surg 2012;38:1516-1520

3 Loussouarn G, Lozano I, Panhard S, Collaudin C, El Rawadi C, Genain G: Diversity in human hair growth, diameter, colour and shape. An in vivo study on young adults from 24 different ethnic groups observed in the five continents. Eur J Dermatol 2016;26:144-154.
4 Sperling L: Hair density in African Americans. Arch Dermatol 1999;135:656-658.

5 Loussouarn G: African hair growth parameters. Br J Dermatol 2001;145:294-297.

6 Lee BS, Chan JY, Monselise A, McElwee K, Shapiro J: Assessment of hair density and caliber in Caucasian and Asian female subjects with female pattern hair loss by using the Folliscope. J Am Acad Dermatol 2012;66:166167.

7 Kang H, Kang TW, Lee SD, Park YM, Kim HO, Kim SY: The changing patterns of hair density and thickness in South Korean women with hair loss: clinical office-based phototrichogram analysis. Int J Dermatol 2009;48:14-21.
8 Galliker NA, Trüeb RM: Value of trichoscopy versus trichogram for diagnosis of female androgenetic alopecia. Int J Trichology 2012;4: 19-22.

9 Bates D, Maechler M, Bolker B, Walker S: Fitting Linear Mixed-Effects Models Using lme4. J Stat Softw 2015;67:1-48.

10 Rushton DH, De Brouwer B, De Coster W Van Neste DJ: Comparative evaluation of scalp hair by phototrichogram and unit area trichogram analysis within the same subjects. Acta Derm Venereol 1993;73:150-153.

11 Bernstein RM, Rasmann WR: The aesthetics of follicular transplantation. Dermatol Surg 1997; 23:785-99. 